\title{
ADAPTIVE POTENTIAL ASSESSMENT OF FUTURE TEACHERS AT THE FIRST STAGE OF THEIR PROFESSIONAL TRAINING \\ Lyudmila N. Voloshina $^{1^{*}}$, Lyudmila K. Buslovskaya ${ }^{2}$, Alexey Ju. Kovtunenko ${ }^{3}$, Yulia P. Ryzhkova ${ }^{4}$, Yulia A. Prokopenko 5 \\ 1,2,3,4,5 Belgorod State University, Belgorod, 85, Pobedy Street, Russia. \\ Email: *voloshina_1@bsu.edu.ru
}

Article History: Received on $21^{\text {st }}$ August 2019, Revised on $29^{\text {th }}$ September 2019, Published on $06^{\text {th }}$ November 2019

\section{Abstract}

Purpose of the study: The topicality of the research is determined by the social order for a healthy personality, awareness of education possibilities to improve the adaptative potential, competitiveness, and activity.

Methodology: The assessment of the health state was based on the medical examination results in the clinic of Belgorod National Research University. Somatometric, somatoscopic and physiometric methods were used to define the functional state of the students' organism.

Results: The health of a growing person starts with the health of his family and the teacher. The quality of the pedagogical strategy and the tactics of healthy generation education are defined by the teacher's ability to design a personal model of safe behavior and to assess his own health adaptive risks and students too. Adaptative potential assessment of a future teacher as an integral health indicator at the primary stage of his professional training will determine the measures to prevent misadaptation and design strategies for personal safe behavior.

Applications of this study: This research can be used for the universities, teachers, and students.

Novelty/Originality of this study: In this research, the model of the Adaptive Potential Assessment of Future Teachers at the First Stage of their Professional Training is presented in a comprehensive and complete manner.

Keywords: adaptative potential, future teachers, physical activity, misadaptation, health, stress, body functionality.

\section{INTRODUCTION}

The most important prerequisites for teacher's successful training are to create an environment promoting the ideas of safe and healthy behavior and to gain his own experience in organizing safe conditions for education. In the future, it will be realized in the educational activities of students. According to some scientists, one of the conditions is to solve the problems is assess the organism adaptative capacity as an integral criterion of health and to design the measures to prevent maladaptive states of future teachers (Tyumaseva et al, 2018; Yefimova et al, 2016).

Health and a healthy lifestyle have not only personal, but also professional importance for the students getting degree in teaching (Pedagogical Education) according to the requirements of the Federal State Educational Standard of Higher Education (FSES HE) in Russia. It means to develop certain universal competencies reflecting the willingness to solve students' problems of health protection and their own. A future teacher must have the competence to create safe living conditions, including emergencies.

The document published by the Interdepartmental Commission on health protection of the population in the Russian Federation proves the decrease in the overall health level of the population at the age groups from 5 to 25 years in this temporary context. Besides, they admit the increase in the frequency and severity of the disease, the occurrence, and spread of pathological conditions (Gilev et al, 2016). The analysis of the current research shows that the incidence rate and health deterioration of future students start happening at school. In a number of native and foreign publications, it is noted that about $50 \%$ of University students have deviations in their health. The most common pathologies are musculoskeletal and cardiovascular system diseases, visual impairment (Yefimova et al, 2016; Gilev et al, 2016; Szemik et al, 2019). The analysis of our research results shows that recently the number of students with a special medical group in Russian universities tends to increase (Suvorova et al, 2017).

Such factors as large information load, lack of exercise (hypodynamia), neuro-emotional stress, educational process intensity, unfavorable ecological situation affect the functional state, efficiency and health of young people (Moskovchenko et al, 2019; Kötter, 2019;). University education objectively leads to significant stress of students' compensatory-adaptive systems. Foreign scientists also admit the tendency to reduce stress resistance of modern students, their psychosocial well-being during the period of study at the University. It should be emphasized that the problem is international in nature. The specific student life contributes to the deterioration of health. The breaking of educational stereotype and the formation of new forms accompany the transition from school to university. It happens in the conditions of increased emotional and psychological stress for students. The first and second-year students have a period of acute adaptation. It is accompanied by a significant tension in the body's regulation systems and the growth of pathology (Zakharov et al, 2018; Kiekens et al, 2019; Chen \& Chen, 2019).

The aim of our research was to study and assess the functional state, health and adaptation problems of future teachers at the primary stage of their professional training at the university. 
To achieve this goal, the following tasks were set: to determine the level and harmony of students' physical development; assess the health of students; to identify the problems of future teachers' adaptation to the University educational environment; to determine the opportunities of overcoming the existing problems.

Data and research methods: The research was conducted at the Pedagogical Institute of Belgorod National Research University in 2017-2018. A total of 136 1st year students were examined. The anthropometric methods such as somatoscopy, somatometry, physiometry were used to determine the physical development of students. The assessment of health state was based on the data of the medical examinations results from the university clinic. We calculated systolic (SV) and minute blood volume (MBV), vegetative Kerdo index (VKI), Hildebrant inter-system relationship index (Q). The method of Spielberger and Hanin was used to reveal the level of personal anxiety. The current functional status was assessed with a multi-factor test of subjective scaling "SAN". The strength of nerve processes was evaluated by the method of tepping test. Daily biorhythms were assessed according to Horn D. - Esterberg O. but in the modification of A. A. Putilov. The research was done during the first term. Adaptive compensatory mechanisms were determined by the adaptive potential (AP).

\section{RESEARCH METHODS}

The assessment of the health state was based on the medical examination results in the clinic of Belgorod National Research University. Somatometric, somatoscopic and physiometric methods were used to define the functional state of the students' organism. The adaptative potential of the organism was measured by Bayevsky's method. The method of Spielberger (STAI) and Hanin was used to assess the level of personal and reactive anxiety. The emotional and behavioral components of adaptation were studied with the test of multifactorial subjective scaling "SAN". The study showed that only $5 \%$ of future teachers at the first stage of training are practically healthy, the others have some deviations in health, physical development, and chronic pathology. Generally, first-year students are characterized by the adaptation processes voltage, especially during their session period. It necessitates to improve the University health-saving environment and to create professional models of healthy behavior.

\section{EMPIRICAL RESULTS}

The analysis of the research results of the level and harmony of first-year students' physical development showed that $45 \%$ of them have deviations from the norm in physical development, in most cases they are disharmonious.

The analysis of students' medical records showed that only $10 \%$ of them were practically healthy, the rest had some kind of chronic pathology. Postural disorder, vegetative-vascular dystonia, chronic tonsillitis, chronic gastritis prevail among other pathologies. Some students with chronic sinusitis, cystitis, myopia, and other diseases were also identified. The fact is that $62 \%$ of them have one disease, $31 \%$ - two, and $7 \%$ - three or more.

The nervous system overstrain especially with hypodynamia leads to the dysfunction of its autonomic parts which determine the possibility of adaptation. A number of studies show some significant changes in cardiohemodynamic and cardiorespiratory parameters of young people. Therefore, in our experimental work, we paid special attention to the state of the cardiovascular system. The analysis of first-year students' electrocardiograms showed that $38.9 \%$ of people had the state of norm, the rest had some kind of heart pathology. Thus, we found out that $52.9 \%$ of students had incomplete blockade of the right leg of his band. $5.8 \%$ - had preexcitation syndrome and wandering pacemaker, 2.2\% - premature atrial contraction.

The hemodynamic parameters are the universal indicators of adaptative processes in the body to predict it's the functional state and adaptive capabilities. Students' indicators of cardiovascular system parameters are shown in chart 1.

The significant changes in the basic cardiovascular system parameters of the first-year students should be emphasized.

At the beginning of the first term, the students had the average values of systolic (SBP) and diastolic (DBP) blood pressure, heart rate (HR), systolic (SVB) and minute volumes (MVB) of blood within the physiological norm.

During the winter session, all these parameters significantly increased on average.

Chart 1: Parameter indicators of first-year students' cardiovascular system

\begin{tabular}{llllll}
\hline Time of research & SBP, mil Hg & DBP, mil Hg & HR, per minute & SVB, mil & $\begin{array}{l}\text { MVB, liter per } \\
\text { minute }\end{array}$ \\
\hline The beginning of the first term & $114.8 \pm 1.0$ & $73.9 \pm 0.8$ & $75.5 \pm 1.1$ & $62.6 \pm 0.7$ & $4.7 \pm 0.1$ \\
\hline First examination period & $115.6 \pm 1.1$ & $73.5 \pm 0.9$ & $80.0 \pm 1.1^{*}$ & $67.4 \pm 0.7 *$ & $5.1 \pm 0,1^{*}$ \\
\hline
\end{tabular}

Note: * accuracy of changes is compared with the first term results $-\mathrm{p}<0.05$

Vegetative homeostasis was evaluated according to the value of the Hildebrant index (Q) as the characteristics of intersystem relationship in the cardiorespiratory system. The value from 2.8 to 4.8 units corresponds to the state of the norm. The deviation in one direction or another indicates a misalignment in the activity of visceral systems (Kosovanova et al, 
2003). At the beginning of the first term and during the first examination period, the average values of Q were in the upper limits of the norm. At this time, $70 \%$ of students had normal intersystem relationships in the cardiorespiratory system. $30 \%$ were observed with misalignment in the cardiovascular and respiratory systems.

The analysis of students' WIC in the first term showed that $56 \%$ of students are sympathotonics with ergotropic regulation mechanism prevalence. $38 \%$ of students are vagotonics with some predominance of trophotropic mechanism. Amphotonic or the balance of the nervous system autonomic parts was observed among $6 \%$.

During the first examination period, the number of sympathotonics increased to $83 \%$, but vagotonics and amphotonics decreased. The average values of Kerdo index were significantly increased. In most cases the functional state of the autonomic nervous system determines the course and outcome of the adaptative processes of the body. The majority of the respondents were observed with a high level of the sympathetic department activity which is the basis of exposure to psycho-emotional stress, a high level of anxiety and as a result of failure of adaptation (Zakharov et al, 2018).

The testing of students with a multi-factor test of subjective scaling "SAN showed that at the beginning of the term $44.9 \%$ of students assess their health as excellent, $47.1 \%$ as good, and $8.0 \%$ as bad\%. These results prove an inflated subjective assessment of the general state and explicit fatigue. It should be noted that $71.0 \%$ of students in the academic term defined their mood as excellent, $27.0 \%$ - as good and $2.0 \%$ - as bad. In this period $55.0 \%$ of students had average activity, $38.0 \%-$ high, $7.0 \%$ - low. During the session students, health and mood became worse in their own opinion. The number of students with good and excellent health has decreased. On average, the number of students with poor health and $14.5 \%$ with bad mood increased by $10 \%$. The activity of the students was quite high. But the significant degree of fatigue in $38.4 \%$ of students causes concern. During the examination session, the number of students with fatigue increased by $15 \%$.

The analysis of the tapping test results revealed that the majority of the surveyed first-year students have a weak and medium-weak nervous system (85\%). Students with strong nervous processes are13\%, with average strength - $2 \%$ of all surveyed. The intermediate day type - "dove" predominates among the biological circadian rhythms of the first-year students.

The process of students' adaptation to new conditions of their life and learning is accompanied by an increase in the level of personal anxiety. The analysis showed that at the beginning of training only $6 \%$ of first-year students had normal psycho-emotional state and good adaptability. The others showed signs of stress to some extent, $60 \%$ of the students were moderately anxious, and $34 \%$ of all surveyed had a high level of anxiety, i.e. were under stress. This is probably due to the primarily alteration of dynamic stereotypes that firmly formed in the previous conditions of their life and education. During this period, the average values of personal anxiety ranged from $41.8 \pm 0.7$ to $43.7 \pm 0.8$ points, which corresponds to a moderate level of anxiety.

The highest anxiety and poor adaptation were typical for the period of the first examination session. The number of students with high anxiety increased to $56 \%$. The average values of personal anxiety ranged from $45.7 \pm 1.0$ to $47.1 \pm 0.9$, which is significantly higher than at the beginning of the first term. High anxiety indicates poor adaptation, the presence of emotional and behavioral signs of chronic stress, which often lead to somatic disorders and nervous breakdowns. This is confirmed by the results of the analysis of students' adaptation potential (AP) (chart. 2). The degree of adaptation is determined depending on the value of AP: satisfactory adaptation - 2.10 points and below; voltage of adaptation mechanisms - 2.11-3.20 points; unsatisfactory adaptation - 3.21-4.30 points; failure of adaptation -4.30 points and above.

Adaptation potential of first-year students

\begin{tabular}{ll}
\hline Research time & AP, points \\
\hline The beginning of the first term & $2.13 \pm 0.02$ \\
\hline First examination period & $2.16 \pm 0.02$ \\
\hline
\end{tabular}

It should be pointed out that at the beginning of the first term 57\% of students had a satisfactory level of adaptation potential, $43 \%$ showed a voltage of adaptive mechanisms of adaptation. However, the average values of the adaptive potential were $2.13 \pm 0.02$ points.

During the first examination period, the results of determining AP are the following: $45 \%$ of students had satisfactory adaptive potential, 55\% - stress adaptation mechanisms. It means that the number of students with stress adaptation mechanisms has increased, and the functionality of the body was provided by the reserve. The average values of adaptive potential were $2.16 \pm 0.02$ points, which corresponded to the voltage of adaptation mechanisms. According to V. M. Yefimova, the beginning of studies at the University is accompanied by the stress of adaptation mechanisms, the reduction of organism compensatory-adaptive capabilities, which is reflected in the change of adaptive potential (Yefimova et al, $\underline{2016}$ ).

Based on the analysis of all available information, we identified a group of students with the stress of adaptation processes (maladaptation). The studies conducted in 2014 by our university scientists confirm the tension of compensatory-adaptive mechanisms in students during adaptation. The main factors leading to "failure" of adaptation are the high psychoemotional stress, the intensity, and volume of training loads, the lack of resources, both external and internal, for psychological stabilization of psycho-emotional stress (Yefimova et al, 2016; Szemik et al, 2019; Zakharov et al, 2018). In 
our opinion, one of the reasons that reduce the adaptive capacity of the body is a decrease in students' motor activity during the adaptation period. Kondakov confirmed it in his studies. To reduce the stress of the reaction and increase the adaptive capacity of students with maladjustment it is necessary to conduct comprehensive corrective work. For its design it is recommended to use the developments by Yefimova; Moskovchenko; Tyumaseva and others.

\section{CONCLUSION}

1. At the primary stage, $45 \%$ of future teachers have deviations from the average level of physical development, most of them have disharmonious one.

2. The analysis of the health status of the surveyed freshmen indicates that only $5 \%$ of future teachers are practically healthy, the rest have chronic pathology. Among them, $62 \%$ have one disease, $31 \%$ - two, and $7 \%$ - three or more, indicating the need for comprehensive medical, psychological and pedagogical support of students in the university education.

3. According to the diagnosis of vegetative status, more than half of future teachers are sympathotonics, with a predominance of the ergotropic mechanism of regulation. During the examination period, the number of students with this type of regulation and with mismatch in the activities of the cardiovascular and respiratory systems increases. This is due to the psycho-emotional overstrain, fatigue, irrational nutrition, combined with a lack of motor activity and other factors affecting the current stage of training.

4. The analysis of the research results showed that a high level of general personal anxiety is typical for $56 \%$ of first-year students. It indicates emotional and behavioral signs of chronic stress. The results confirm the need for preventive measures aimed at designing techniques of behavior and motor activity self-regulation, from the first university days.

First-year students are characterized by the tension of adaptation processes. During the session, the number of students with satisfactory adaptation decreases, with the stress of adaptation processes - increases by an average of 7-12\%. Thus, the health-saving component of the educational environment requires improvement in the organization of physical culture and health, medical and preventive, psychological and pedagogical work to overcome maladjustment and develop the models of personal safe behavior from the first steps in the teaching profession.

\section{REFERENCES}

1. Popham, W. J. (2009). Assessment literacy for teachers: Faddish or fundamental?. Theory into practice, 48(1), 411. https://doi.org/10.1080/00405840802577536

2. Chen, W. L., \& Chen, J. H. (2019). Consequences of inadequate sleep during the college years: Sleep deprivation, grade point average, and college graduation. Preventive medicine, 124, 23-28. https://doi.org/10.1016/j.ypmed.2019.04.017

3. Gilev, G. A., Popkov, A. I., \& Romanovsky, S. K. (2016). The relevance of the motor activity of students outside the curriculum grid. Physical culture and health, 1(48), 59-62 (In Russian).

4. Goldhaber, D., \& Hansen, M. (2010). Assessing the Potential of Using Value-Added Estimates of Teacher Job Performance for Making Tenure Decisions. Working Paper 31. National Center for Analysis of Longitudinal Data in Education Research. Kiekens, G., Hasking, P., Claes, L., Boyes, M., Mortier, P., Auerbach, R. P., ... \& MyinGermeys, I. (2019). Predicting the incidence of non-suicidal self-injury in college students. European psychiatry, 59, 44-51. https://doi.org/10.1016/j.eurpsy.2019.04.002

5. Kötter, T. (2019). Starting points for resilience promotion in medical education: What keeps future doctors healthy?. Aktuelle Urologie, 50(2), 190-194. https://doi.org/10.1055/a-0834-5954

6. Moskovchenko, O. N., Zakharova, L. V., Tretyakova, N. V., Kattsin, O. A., \& Savolaynen, G. S. (2019). Application of hardware and software complex for individualisation of students' sport and recreational physical activities. Obrazovanie i Nauka, 21(1), 124-149. https://doi.org/10.17853/1994-5639-2019-1-124-149

7. Lantolf, J. P., \& Poehner, M. E. (2007). Dynamic assessment of L2 development: Bringing the past into the future. Journal of Applied Linguistics and Professional Practice, 1(1), 49-72. https://doi.org/10.1558/japl.v1i1.647

8. Volante, L., \& Fazio, X. (2007). Exploring Teacher Candidates' Assessment Literacy: Implications for Teacher Education Reform and Professional Development. Canadian Journal of Education,30(3), 749-770. https://doi.org/10.2307/20466661

9. Suvorova, A. V., Iakubova, I. Sh., \& Chernyakina, T. S. (2017). Dynamics of indices of the state of health of children and adolescents in the city of ST. Petersburg for 20 years. Gigiena $i$ Sanitariya, 96(4), $332-338$. https://doi.org/10.18821/0016-9900-2017-96-4332-338

10. Szemik, S., Kowalska, M., \& Kulik, H. (2019). Quality of life and health among people living in an industrial area of Poland. International journal of environmental research and public health, 16(7), 1221. https://doi.org/10.3390/ijerph16071221

11. Tyumaseva, Z. I., Orekhova, I. L., Valeeva, G. V., Salamatov, A. A., \& Kalugina, E. V. (2018). The institution of tutoring in health-preserving: Risk and sustainability factors. Obrazovanie $i$ Nauka, 20(9), $139-157$. https://doi.org/10.17853/1994-5639-2018-9-139-157 
12. Yefimova, V. M., Skoromnaya, N. N., \& Yatskova, L. P. (2016). Organism adaptive capacity evaluation in the system of junior students' pedagogical support. Problems of modern pedagogical education,53(1), 110-119 (In Russian).

13. Zakharov, E., Smelysheva, L., Artenian, N., \& Kotenko, I. (2018). Effects of emotional stress on plasma and saliva adrenalin and noradrenaline in students. GAZZETTA MEDICA ITALIANA ARCHIVIO PER LE SCIENZE MEDICHE, 177(3), 123-130.

14. Antonenko, P. D., \& Thompson, A. D. (2011). Preservice teachers' perspectives on the definition and assessment of creativity and the role of web design in developing creative potential. Education and Information Technologies, 16(2), 203-224. https://doi.org/10.1007/s10639-009-9112-1

15. Kale, U. (2014). Can they plan to teach with Web 2.0? Future teachers' potential use of the emerging web. Technology, Pedagogy and Education, 23(4), 471-489. https://doi.org/10.1080/1475939X.2013.813408

16. DeLuca, C., Chavez, T., Bellara, A., \& Cao, C. (2013). Pedagogies for preservice assessment education: Supporting teacher candidates' assessment literacy development. The Teacher Educator, 48(2), $128-142$. https://doi.org/10.1080/08878730.2012.760024

17. DeLuca, C., \& Bellara, A. (2013). The current state of assessment education: Aligning policy, standards, and teacher education curriculum. Journal of Teacher Education, 64(4), $356-372$. https://doi.org/10.1177/0022487113488144

18. Brookhart, S. M. (2011). Educational assessment knowledge and skills for teachers. Educational Measurement: Issues and Practice, 30(1), 3-12. https://doi.org/10.1111/j.1745-3992.2010.00195.x

19. Popham, W. J. (2011). Assessment literacy overlooked: A teacher educator's confession. The Teacher Educator, 46(4), 265-273. https://doi.org/10.1080/08878730.2011.605048

20. Plake, B. S. (1993). Teacher assessment literacy: Teachers' competencies in the educational assessment of students. Mid-Western Educational Researcher, 6(1), 21-27. 